\title{
Considerations on the Thermo-hygrometric and Luminous Microclimate of a Museum Building. A Case Study Messina Museum
}

\author{
Mauro Cannistraro $^{1 *}$, Cecilia Guglielmino ${ }^{2}$ \\ ${ }^{1}$ Department of Architecture, University of Ferrara, Italy \\ ${ }^{2}$ Department of Engineering, University of Messina, Italy
}

Corresponding Author Email: mauro.cannistraro@gmail.com

https://doi.org/10.18280/ti-ijes.632-414

Received: 13 February 2019

Accepted: 22 April 2019

\section{Keywords:}

comfort thermo-hygrometric, microclimate for the conservation of works of art, comfort luminous, air quality inside of museum micro-environments, techniques and solutions for the containment of energy consumption

\begin{abstract}
The microclimatic control of the environments destined to the exposure and the conservation of the works, understood as control of the parameters of temperature, relative humidity, lighting engineering, and air quality inside both macro-environments (exhibition halls, warehouses, etc.) and of museum micro-environments; (shop windows, storage and transport containers), has long been of particular interest to museum curators. It is well known that the environmental parameters mentioned above can triggering or aggravating degradation processes through chemical, physical or biological mechanisms and how they contribute to increase or reduce the "life expectancy" of a cultural asset. This article shows the first results of a survey aimed at evaluate the conditions of the thermo-hygrometric and luminous microclimate for the conservation of works of art within the new seat of the Regional Museum of Messina. In this preliminary phase of a larger study, a simulation was conducted through a software to verify the main parameters of the passive behavior of the museum shell, in order to plan a subsequent campaign of investigations and measures on the compatibility of the microclimate with the regulatory requirements of the conservation of works of art and their use by the public and to provide information on possible adjustments plant engineering, also identifying techniques and solutions for the containment of energy consumption, always high in this type of structures.
\end{abstract}

\section{INTRODUCTION}

The works of art are inevitably exposed to the phenomenon of degradation, in relation to the unstable character of the materials that constitute them [1-3].

In fact, degradation occurs naturally and progressively with the aging of the object and the alteration of its chemical and physical properties.

At international level, specific rules have been developed since the last few years storage conditions and risk assessment tools, which define the methodologies of preventive conservation of arts works.

It is known that unsuitable microclimatic conditions and non-management procedures correct they can accelerate the processes and lead, in the long run, to the total loss of the preserved of the works.

The fundamental element of museum policies and collection care is therefore the concept of "Preventive conservation" which must be based on appropriate policies based on the adoption of behaviors and of technical precautions, applicable with continuity, aimed at preventing or slowing down the phenomena of degradation, reducing them to the minimum intensity [4-7].

In fact, prevention refers to all the activities suitable for limit the risk situations related to the cultural asset in its context. A correct management policy, based on "preventive conservation", allows, therefore, to avoid, or at least to postpone in time, the restoration intervention that represents an invasive intervention and potentially destructive.
In prevention interventions an important role is played by the control of microclimatic parameters, of lighting and air quality), they should be given the highest priority.

The control of environmental parameters, intended as control of average values and temporal gradients, it is fundamental for the optimal conservation of the collections. In Italy, the Ministerial Decree 10/05/2001 "Act of address on the technical-scientific criteria and on the standards of operation and development of museums "and the UNI 10829 standard "Heritage of historical and artistic interest. Then measurement and analysis of the environmental conditions, with comparison the recommended reference values they allow a good maintenance and conservation of the works of art.

The ASHRAE Handbook "HVAC Applications" defines the thermo-hygrometric control classes environments in which works of art can be preserved, providing indications on fluctuations permitted in the short and long term.

The objective of the microclimatic analysis of a museum building is a thorough knowledge of the system building plant and its potential for microclimatic control.

This analysis depends on numerous factors such as the type of building envelope (light, medium or heavy, isolated, not isolated ...), its air permeability and the type of system present (without plant, with plant water system, all-air or mixed airwater system).

The microclimatic analysis in-depth it can also allow the environmental certification of the examined area.

The verification of the microclimatic quality level of the exhibition areas must be assessed through continuous 
monitoring of microclimatic conditions on an annual basis so as to cover the various seasons and the different plant layouts.

As suggested by the UNI 10829 standard, an analysis of the monitored physical quantities performed through hourly measurement, allows you to acquire a sufficiently in-depth knowledge of the temporal trend of the values of the same quantities [8-9]. Detailed analysis with monitoring data processing, must be performed statistically on average hourly and hourly and daily values of the parameters taken into consideration.

It is important to emphasize that the microclimatic quality of an internal environment can be expressed through the following specific indexes [10-23]:

- Performance Index (IP), which expresses "the percentage of time in which the magnitude under examination is keeps within the chosen field deemed acceptable".

- Deviation Index (IS), is related to storage conditions and is evaluated as the percentage of time, or measured points, for which the environmental parameters detected fall outside the acceptable range of values.

Complete control of the temperature and relative humidity values of indoor air is possible by the use of air conditioning systems, all air or mixed air/water, which also represent the only one effective provision for the control of pollutants in museum environments (removal and dilution of harmful substances).

These plants unfortunately have a negative aspect represented by the high cost of both installation and management.

An alternative to the local control of the exhibition rooms of the museum environment is represented by the adoption of appropriate containers (display cases) within which to place the works; in such containers the microclimate will be checked only locally.

The use of museum display cases makes it possible to respond to safety and protection needs (from interventions intentional or unintentional), to control the microclimate (indoor air temperature, humidity relative, concentration of gaseous and air-suspended pollutants, levels of exposure to radiation electromagnetic fields), and use by the public (optimization of the exhibition of the works and them enhancement).

The possibility of satisfying the control of thermo hygrometric parameters can be provided by passive control of humidity. These systems based on the use of hygroscopic materials must be properly sized function of the characteristics of the container itself (volume, air tightness ...) and performance request.

\section{THE MUSEUM STRUCTURE AND THE CASE STUDY}

\subsection{The museum structure}

The quality of the museum institution must not be evaluated in relation to the collections possessed, to the attraction on the public, to the physical dimension, to the result of an unsupported technical evaluation from quantitative values, but in relation to the ability to satisfy specific management needs of the museum, at the collection care and services to the public.

The structures of the museum, dedicated to providing services to collections, personnel and the public, must be evaluated with reference to the quality of the services rendered by them, rather than to the characteristics of the physical organisms that constitute them (building, exhibition spaces, technological equipment, etc.).

For them must be considered the performance standards related to the expected results, rather than supply standards related to the requirements of the building-systems system.

The facilities must have the ability to meet the needs of its collections, its staff and of the public, they must therefore be able to achieve specific quality objectives.

The structures must also be able to be serviced, that is, such that they can be kept efficient over time, accessible and recognizable, and must comply with the mandatory provisions and suitable for achieving predetermined quality objectives.

To define the characteristics of the structures of a museum we must consider 8 classes of needs, divided into 3 macro areas: collection, personal and public.

For the collection, the needs connected with:

(1) exposure to the public of the collection;

(2) conservation of the collection over time;

(3) registration and documentation of the collection;

(4) the restoration of the objects making up the collection.

For the staff, the needs to do considered are:

(1) staff of the institution during the museum operation.

(2) those who visit the museum;

(3) to connect with the educational function of the museum;

(4) to connect with the research and study functions of the museum.

The properties and characteristics for the staff, the needs are considered:

(1) staff of the institution during the museum operation.

(2) those who visit the museum;

(3) connected with the educational function of the museum;

(4) connected with the research and study functions of the museum.

The properties and characteristics, that give the service provided by the structural elements are the capacity to meet the needs.

Indeed, there is a certain correspondence to every quality objective relating to a different macro area number of parameters to be checked.

In the following Table 2, taken from the Ministerial Decree of 10 May 2001 and by the UNI 10829: 1999 Standard, reported some reference values of the parametrs sizes.

\subsection{The case study}

The Regional Museum of Messina, completed in 1990, stands on the esplanade of S. Salvatore dei Greci, to the church of the same name which stood here until the earthquake of 1908 , overlooking the coastal area.

The museum building is located, as shown in Figure 1 below, north of the city of Messina, at the intersection of two busy roads, the Viale Annunziata that cuts across the urban fabric towards the sea and the Viale della Libertà that follows the coastline.

The eastern front of the building, which looks over the strait, appears in part free from constructions and obstructions of various kinds; the same applies to the northern one which, due to the presence of the road axis, maintains a sufficient distance from the buildings facing.

The south and west fronts, on the other hand, are close to buildings and buildings of varying height and varying istances. 
Table 2. Recommended thermo-hygrometric values to ensure optimal conditions

\begin{tabular}{|c|c|c|c|c|}
\hline Handworks & \multicolumn{2}{|c|}{ Relative Humidity (\%) } & \multicolumn{2}{|c|}{ Air Temperature $\left({ }^{\circ} \mathrm{C}\right)$} \\
\hline Iron armor, weapons & \multicolumn{2}{|r|}{$<40$} & \\
\hline ivories, bones & \multicolumn{2}{|r|}{$45-65$} & \multicolumn{2}{|r|}{$19-24$} \\
\hline $\begin{array}{l}\text { ivories, bones } \\
\text { Bronze }\end{array}$ & \multicolumn{2}{|r|}{$<55$} & \multicolumn{2}{|r|}{..} \\
\hline paper, papier-mache & \multicolumn{2}{|r|}{$50-60$} & \multicolumn{2}{|r|}{$19 \ddot{-24}$} \\
\hline anatomical collections & \multicolumn{2}{|r|}{$40-60$} & \multicolumn{2}{|r|}{$19-24$} \\
\hline mineralogy collections & \multicolumn{2}{|r|}{$45-60$} & \multicolumn{2}{|r|}{$<30$} \\
\hline $\begin{array}{l}\text { marbles and stones leather, } \\
\text { leather and parchment }\end{array}$ & \multicolumn{2}{|r|}{$50-60$} & \multicolumn{2}{|r|}{..} \\
\hline Magnetic disks and tapes & \multicolumn{2}{|r|}{$40-60$} & \multicolumn{2}{|r|}{$10-21$} \\
\hline $\begin{array}{l}\text { Herbariums and botanical } \\
\text { collections }\end{array}$ & \multicolumn{2}{|r|}{$40-60$} & \multicolumn{2}{|r|}{..} \\
\hline Film & \multicolumn{2}{|r|}{$30-50$} & \multicolumn{2}{|r|}{$-5-+15$} \\
\hline Photographs (Black White) & \multicolumn{2}{|r|}{$20-30$} & \multicolumn{2}{|r|}{$2-20$} \\
\hline $\begin{array}{l}\text { Insects and entomological } \\
\text { boxes }\end{array}$ & \multicolumn{2}{|r|}{$40-60$} & \multicolumn{2}{|r|}{$19-24$} \\
\hline Oriental lacquers & \multicolumn{2}{|r|}{$50-60$} & \multicolumn{2}{|r|}{$19-24$} \\
\hline Wood & & $40-65$ & & $19-24$ \\
\hline $\begin{array}{l}\text { Painted Wood, polychrome } \\
\text { sculptures }\end{array}$ & & $45-65$ & & $19-24$ \\
\hline Manuscripts book & & $50-60$ & & $19-24$ \\
\hline Ethnographic material & & $40-60$ & & $19-24$ \\
\hline Organic material in general & & $50-65$ & & $19-24$ \\
\hline Plastics & & $30-50$ & & . \\
\hline $\begin{array}{l}\text { Honed metals and alloys; } \\
\text { brass, silver, pewter, lead and } \\
\text { copper }\end{array}$ & & $<45$ & & . \\
\hline $\begin{array}{c}\text { Fumiture with inlays and } \\
\text { lacquers }\end{array}$ & & $50-60$ & & $19-24$ \\
\hline Mosaics and wall paintings & & $45-60$ & $\begin{array}{r}\text { Min } \\
\text { Max } \\
\end{array}$ & $\begin{array}{l}6^{\circ} \mathrm{C} \text { (winter) } \\
5^{\circ} \mathrm{C} \text { (summer) }\end{array}$ \\
\hline $\begin{array}{l}\text { Organic } \\
\text { products }\end{array}$ & $\begin{array}{l}\text { Relative } \\
\text { Humidity } \\
\text { (\%) }\end{array}$ & $\begin{array}{c}\text { Max } \\
\text { variation } \\
\text { Relative } \\
\text { humidity } \\
\end{array}$ & $\begin{array}{c}\text { Air } \\
\text { Temperature } \\
\left({ }^{\circ} \mathrm{C}\right)\end{array}$ & $\begin{array}{c}\text { Max daily } \\
\text { Temperature. } \\
\text { variation }\end{array}$ \\
\hline on canvas & $40-55$ & 6 & $19-24$ & 1,5 \\
\hline on the table & $50-60$ & 2 & $19-24$ & 1,5 \\
\hline Archaeological & $50-60$ & 2 & $19-24$ & 1,5 \\
\hline wet & $\begin{array}{c}50-60 \\
---\end{array}$ & 2 & $\begin{array}{l}19-24 \\
<4^{\circ} \mathrm{C}\end{array}$ & 1,5 \\
\hline $\begin{array}{c}\text { Pastels } \\
\text { watercolors }\end{array}$ & $\begin{array}{l}40-50 \\
\leq 65\end{array}$ & 6 & $\begin{array}{l}18-22 \\
<10\end{array}$ & 1,5 \\
\hline books and & $\overline{45-55}$ & 5 & $<21$ & 3 \\
\hline $\begin{array}{l}\text { manuscript } \\
\text { graphic material }\end{array}$ & $45-55$ & 5 & $<21$ & 2 \\
\hline
\end{tabular}

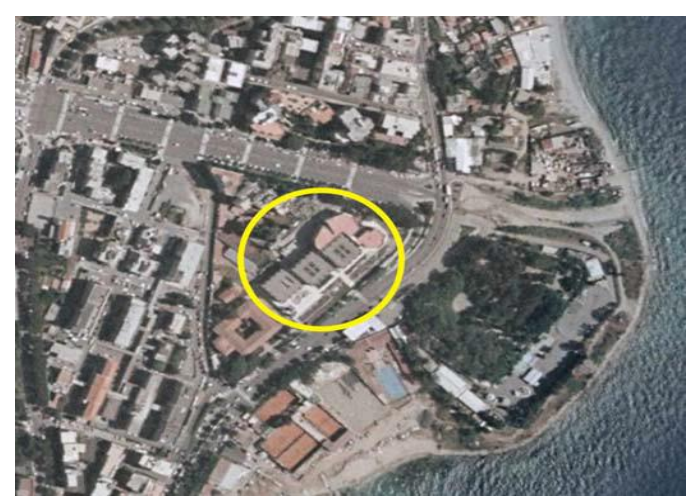

The building has a planimetric layout is constituted by three buildings with at square plan called A, B, C respectively from bottom to top), and three buildings with an irregular plant, named (from left to right) $\mathrm{x}, \mathrm{y}, \mathrm{z}$ which, hinged to building $\mathrm{C}$, at close the plant to the north.

Caesura points between the first three buildings, are two entirely glazed volumes, called "greenhouses".

The museum, currently empty, will host the endowment of works from the current exhibition site, the former Filanda Melligghoff, exhibited in chronological succession according to the distribution of the exhibition spaces in the two plans, shown in Figure 2.

Figure 1. Theregional Museum of Messina 


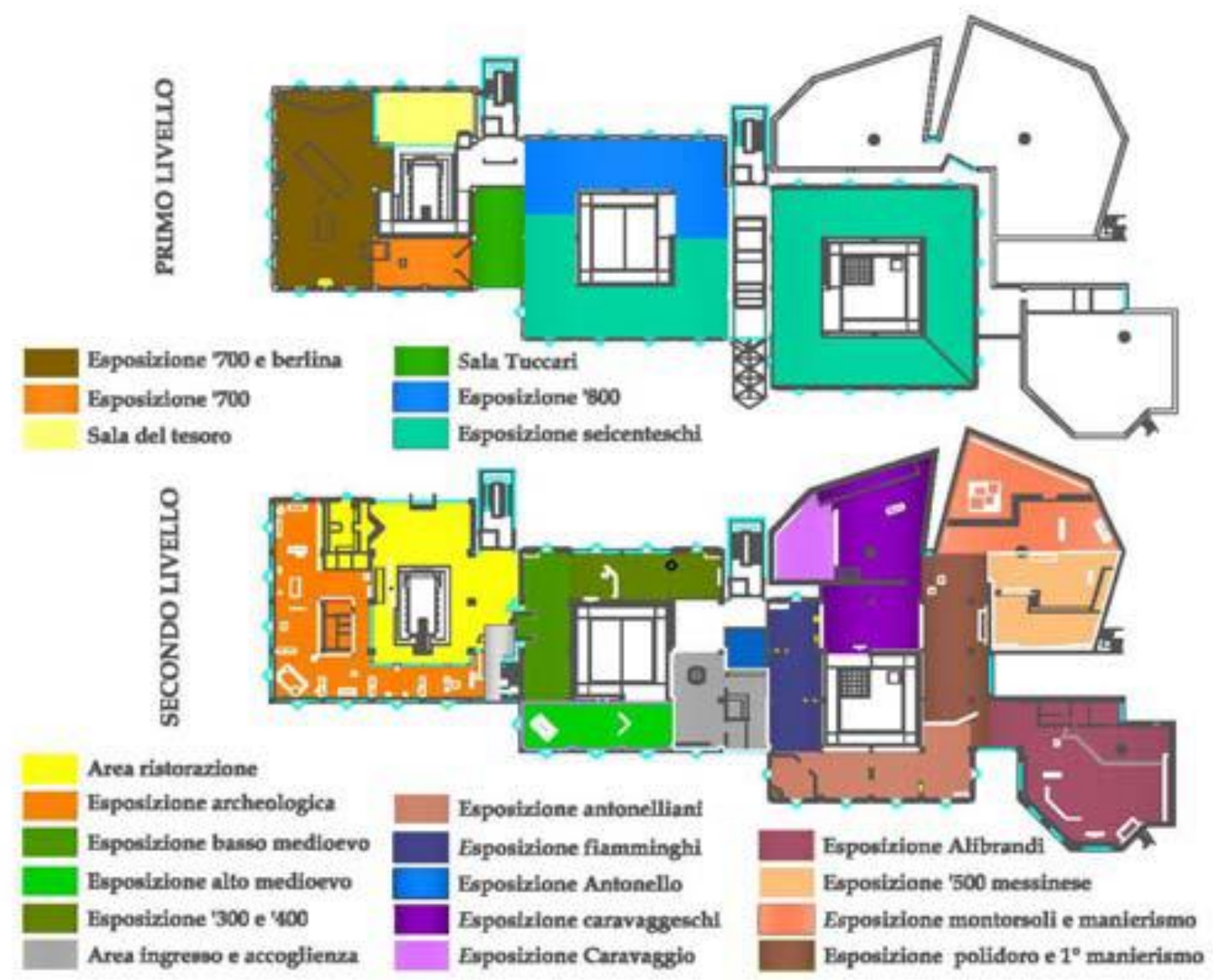

Figure 2. Distribution of exhibition spaces

\section{THE THERMO-HYGROMETRIC MICROCLIMATE}

The control of the microclimate in a museum environment requires specific attention and presents several problems: performance requirements in these environments are significantly higher than those required for spaces intended to maintain a thermo-hygrometric comfort to the occupants [10]. The main objective of controlling the thermo-hygrometric conditions for the conservation of the works of art, is to keep the temperature and relative humidity values as stable as possible throughout the year.

Stability within narrow ranges is required both over the long term, for example stability on a base monthly and yearly, which on the short and very short period, i.e. on a daily and hourly basis.

For the definition of values suitable for conservation, it can be based in the absence of precise indications

by conservators on specific collections, on the indications given on two documents basic in terms of microclimatic control:

The Ministerial Decree 10/05/2001 "Address Act on technical criteria scientific and museum operating and development standards " [4]

The aforementioned UNI 10829.

The latter reports "acceptance ranges" for each type of material and object displayed.

They represent recommended values if they are not set ad hoc on the basis of targeted indications of the conservator who can establish them in relation to the "climatic history" of the exhibited works.

The subsequent choice of the most suitable system solution for climate control is particularly complex: the museum spaces can, in fact, be destined to different functions and in them must be guaranteed good conditions for the conservation of the exhibited works and at the same time for the usability of spaces by visitors.

Sometimes, the thermo-hygrometric conditions required to satisfy the two different purposes are appreciably different: in this case, the conservation of the works assumes a priority position.

In general, it is however necessary to seek and study an adequate compromise between the conditions of microclimatic comfort for art objects and for visitors who crowd the exhibition halls.

\subsection{The luminous microclimate}

To limit the damage caused by light radiation, for most materials, complete darkness it should be the ideal condition for the environment, while to enhance the pleasure of vision it is it is preferable to have natural light conditions, which, due to their specific characteristics, enhance the perception of any object. A painting, belonging to any typology, cannot support, without being modified, the direct incidence of any quantity of light radiation. In the museum space the quality of the luminous environment therefore assumes a fundamental 
importance on quality of the museum.

A very delicate aspect of the problem is the control of natural lighting: light diurnal allows a better vision of colors and shapes; but on the other hand, it is not easily controllable and does not contribute to the conservation of objects due to the presence of large quantities of radiation harmful to materials. We must also add the extreme variability of natural light, in fact it varies both the intensity and color temperature, and these two parameters vary both during the day and during the year.

The UNI 10829 deals with the annual energy exposure, more correctly called "light dose annual", in lux $\cdot \mathrm{h} / \mathrm{year}$, that is the quantity of light that an object receives within a year, obtained adding the illuminance values for each hour of the year.

\section{SIMULATIONS OF THE BUILDING PASSIVE BEHAVIOR}

Given that the development of a survey system is the main purpose of the research, we proceeded, before the monitoring campaign, to carry out a series of simulations, just to identify, on the basis of passive behavior, the critical aspects of the museum building, through those areas where a due to the presence of large glass surfaces, whether they are vertical on the side walls, or skylights on the coverage, overheating of the exhibition areas and over-exposure may occur at high illuminance values, or on the contrary, due to the presence of completely surfaces opaque, one must necessarily resort to artificial lighting alone. The first phase of the study was to prepare a tridimensional model as faithful as possible to reality also providing geo-referencing of the vertices of the building, in order to evaluate correctly the behavior of the same based on the solar paths. For the simulations we used the Ecotect software from SquareOne.

That is a complete tool for the study of buildings that covers a wide spectrum of simulation functions and of analysis and that allows to understand in depth how a building will behave from the point of view of comfort and energy consumption, starting right from the climatic conditions of the place and assuming it as a design element; the interaction between climate and buildings is the basis of the code of Ecotect calculation.

For climate data, a specific file has been prepared, based on the meteorological information of a series historical of over 10 years.

The graph in figure 3 shows the trend of the average temperature values over 24 hours for the 52 weeks of the standard year.



Figure 3. Representation of mean values weekly Temperature for the city of Messina

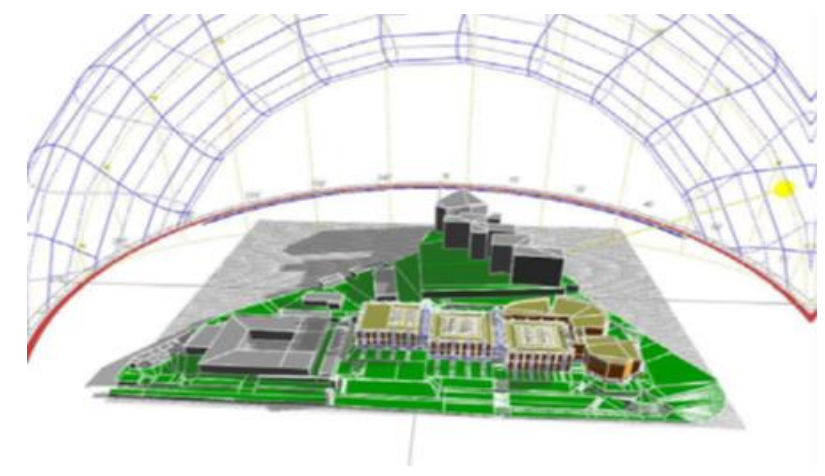

Figure 4. Simulation of annual solar paths
A preventive simulation has allowed us to study the solar paths and therefore to determine which are the areas and the most critical exhibition rooms, both in terms of thermohygrometric and luminous aspects and for which periods of the year. Figure 4 shows the museum model contextualised in a three-dimensional reconstruction of the site.

The first simulations have shown the high values of lighted that represent a peculiar a characteristic of the structure, the long extended form the north-south direction and a modest shelter from the west side, given by the shading of the surrounding buildings. The simulations were carried out every day of the year. The simulations were carried out every day of the year. 
The work shows the most representative simulations of the thermo-hygrometric behavior e of natural lighting.

For the first one the results of the days 26 January and 19 July are reported, while for the second the results relating to the solstices and equinoxes: 21 March, 21 June, 23 September and 22 December.
Figures 5, 6 and 7 show some thermo-hygrometric simulations of the Carrozza halls, of Caravaggio and Tuccari, while Figures 8, 9 and 10 show some simulations regarding the contribution daylighting and related spatial diffusion.

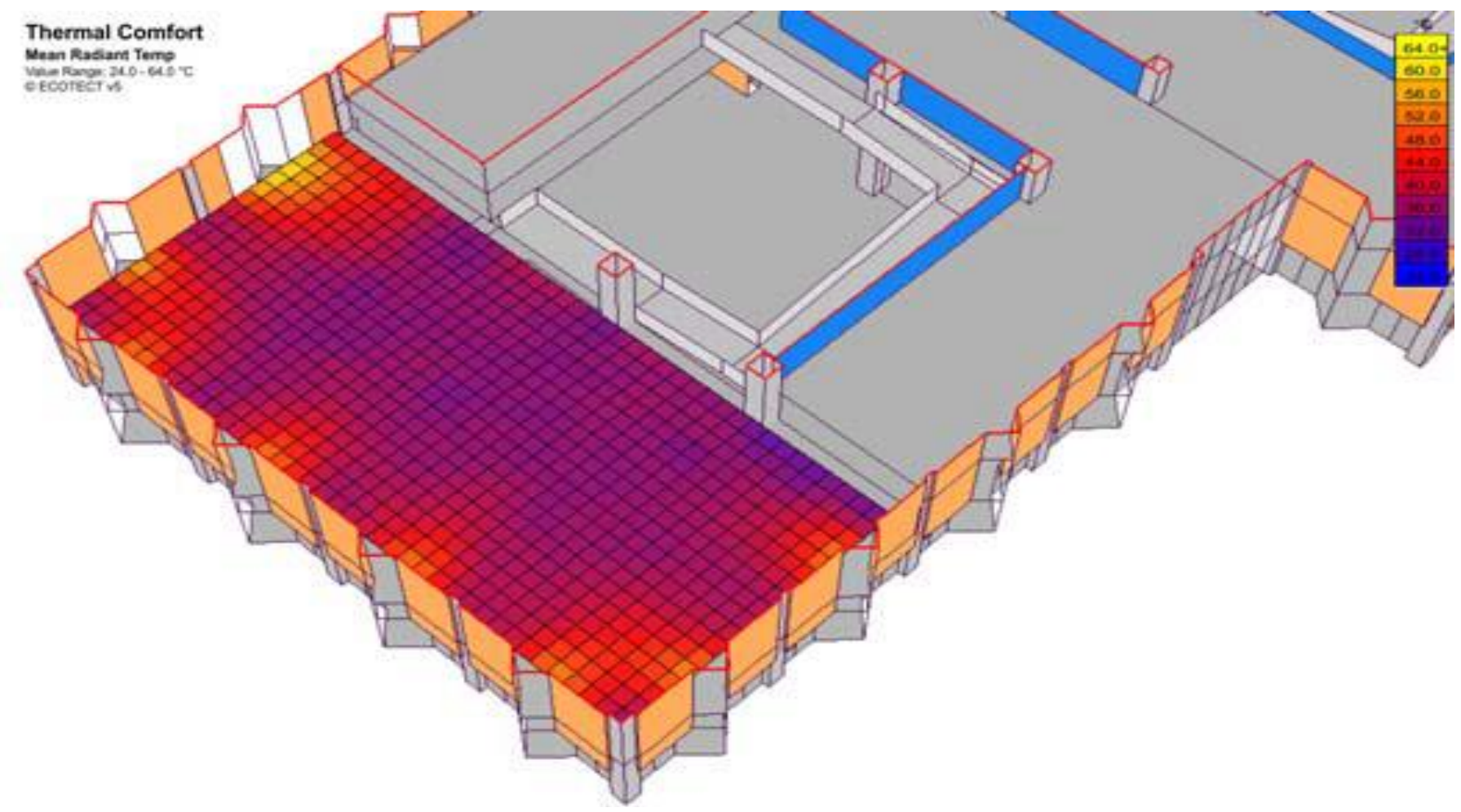

Figure 5. Simulation of $\mathrm{T}_{\mathrm{MR}}$ levels on grid horizontal "Carriage" room

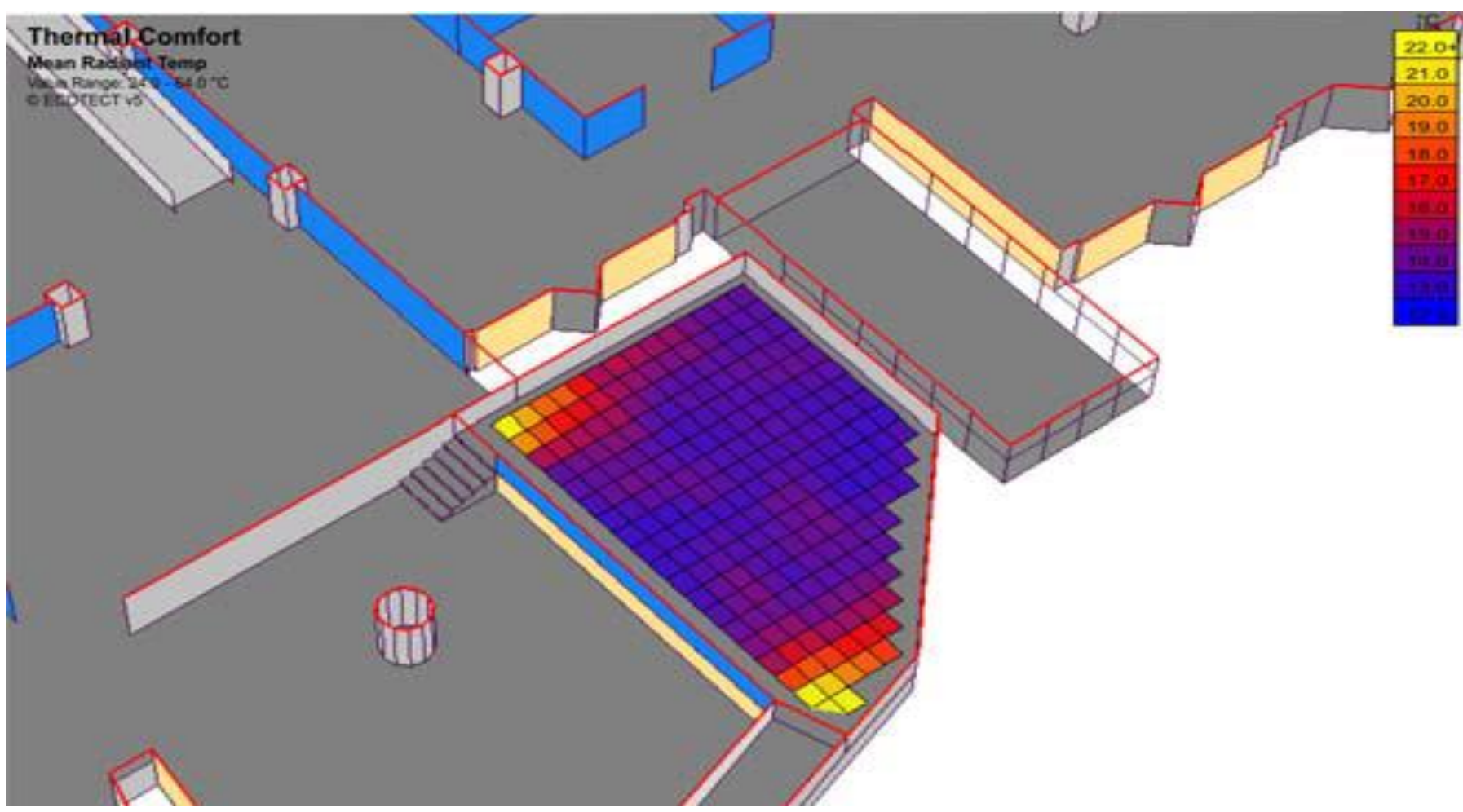

Figure 6. Simulation of $\mathrm{T}_{\mathrm{MR}}$ levels on "Caravaggio" horizontal grid 


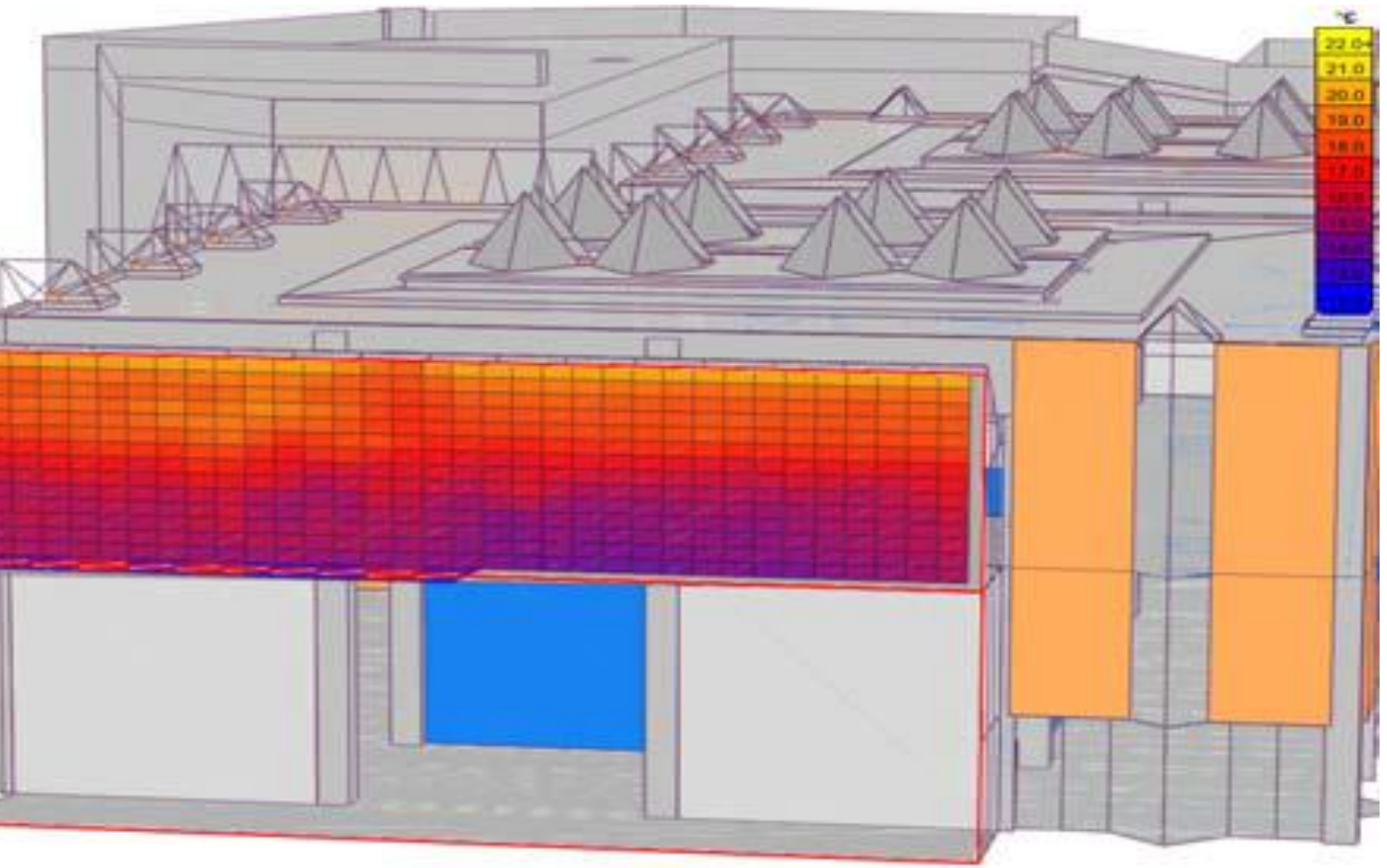

Figure 7. Vertical profile simulation temperature room "Tuccari"

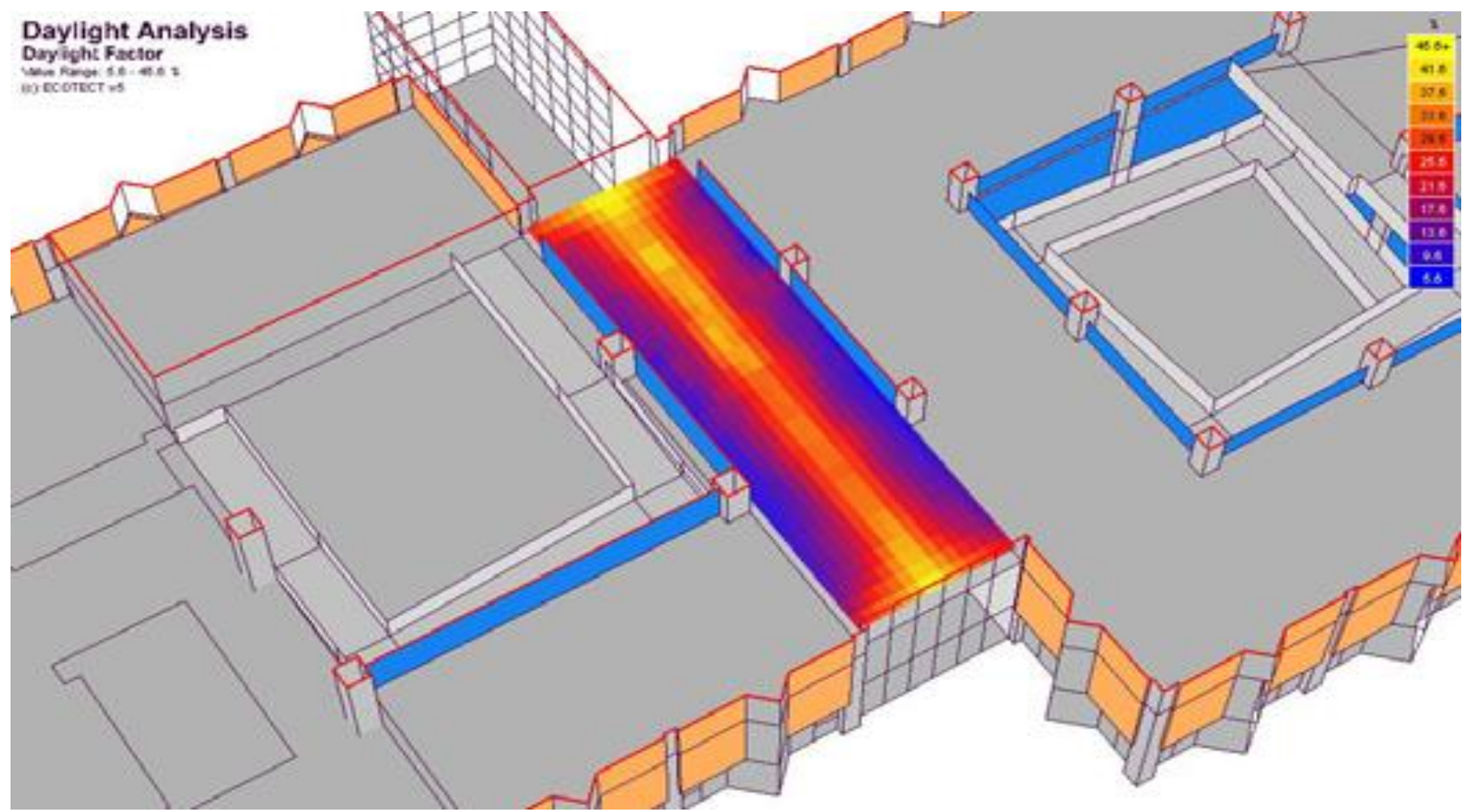

Figure 8. Simulation of daylight factor levels room "Tuccari”, horizontal grid 


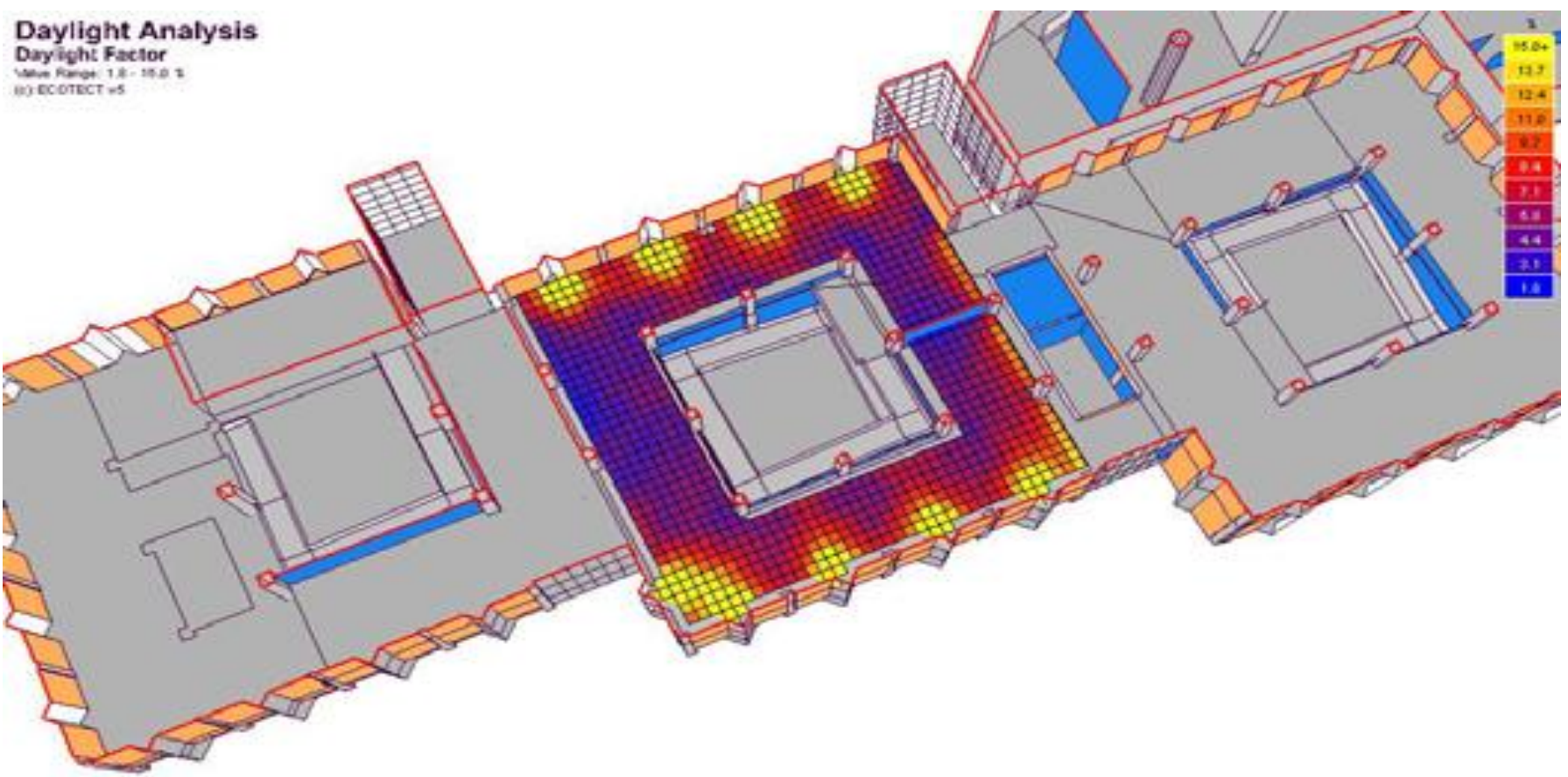

Figure 9. Simulation of daylight factor levels on the horizontal grid of the 17 th century hall

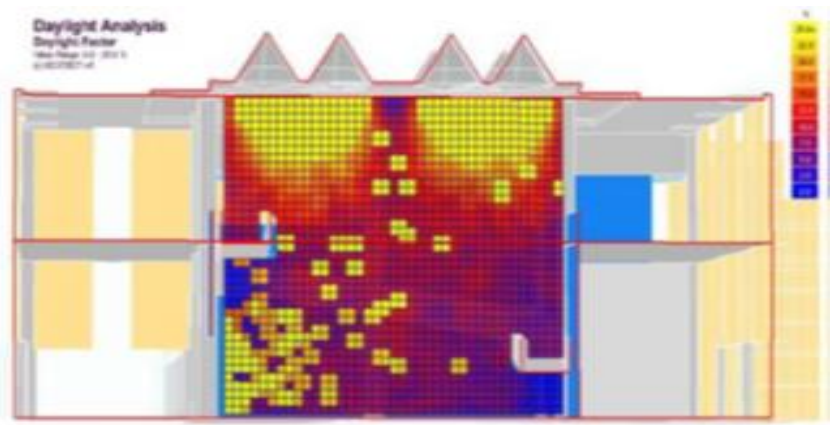

Figure 10. Simulation of daylight levels on vertical grid of the central body

\section{RESULTS AND CONCLUSIONS}

The results of the simulations made it possible to derive a series of data regarding the behavior of the museum building envelope, highlighting some critical issues and providing some indications for the microclimate control, such as passive exploitation of solar energy supplies and optimization lighting and natural ventilation.

The simulations highlighted good passive behavior of the "Caravaggio" and "Alibrandi" rooms. In particular, during the winter period the simulated temperature variations, result very limited, and even in the summer period the oscillations (DT), they keep themselves always very limited.

While in the "Tuccari" and "della carrozza" rooms, the data provided by the simulations are strongly affected by the hourly variations in temperature.

In Figures 11 and 12, the comparison between the external temperature value and the values average simulated temperature, is shown for each of the four rooms.

The simulations of daytime lighting levels, obtained by comparing the levels of external lighting to the simulated daylight factor value, show a high average level on the calculation grid in terms of absolute value, however, from the reading of the aforementioned grids, it appears clear that often the long distribution the whole area of the hall is highly uneven, with obvious accents near the openings.

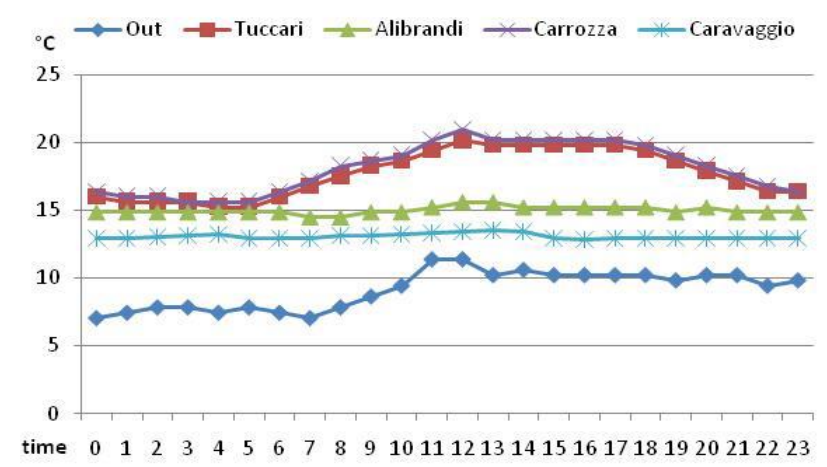

Figure 11. Simulated values for hourly variations temperature - Jan. $26^{\text {th }}$

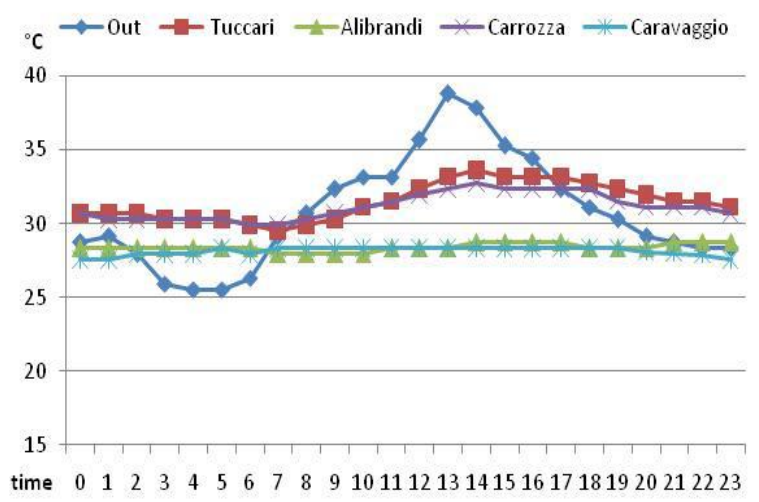

Figure 12. Simulated values for hourly variations temperature 19 July 


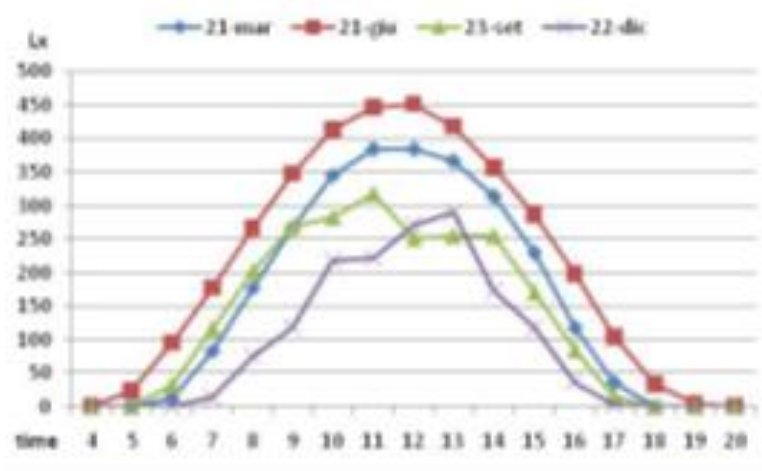

Figure 13. Simulated value for hourly room lighting

Figure 13 shows the trend of the simulated average illuminance value within the 17 th century, calculated by relating the value of the average DF of the room to the value of the external time illumination.

The results of the simulations show a good passive behavior of the museum. In particular, one sufficient availability of natural lighting, due to the narrow and elongated shape of the walls Transparent surfaces results in a modest but inevitable overheating during the summer period in any case it can be offset by the system.

This behavior will be the subject of a subsequent microclimate monitoring investigation.

For rooms with skylights and wide glass surfaces, some systems will be used for the natural lighting control.

Based on the indications provided by the simulations, monitoring will be carried out in a subsequent survey of the various environments for a sufficiently long period.

The methodology to be followed for subsequent monitoring will be divided into two phases: in the first fase, after having subdivided the environment, according to a grid of different dimensions according to the parameters to be detected, then will be acquainted the environmental data using instruments portable and probes connected to a multi-acquisition device. Based on the results obtained and on the indications of the simulations, it will proceed to continuous measurements which will highlight the magnitude of the hourly or seasonal variations in the individual quantities comparing them with the reference values.

\section{REFERENCES}

[1] Harriman L, Brundrett G, Kittler R. (2011). Humidity control design guide for commercial and institutional buildings. ASHRAE 23: 334-358. https://trove.nla.gov.au/version/9763295

[2] Thomson G. (1986). The Museum Environment, Elsevier Editor.

[3] Camuffo D. (1998). Microclimate for cultural heritage.

[4] Costanzo S, Cusumano A, Giaconia C, Giaconia G. (2006). Preservation of the artistic heritage within the seat of the Chancellor ship of the University of Palermo A proposal on a methodology regarding an environmental investigation according to Italian Standards. Building and Environment 41: 1847-1859. https://doi.org/10.1016/j.buildenv.2005.06.010

[5] Saiz-Jimenez C. (2004). Air Pollution and Cultural Heritage. Taylor \& Francis https://doi.org/10.1201/b17004
[6] Watt J, Kucera V. (2009). The Effects of Air Pollution on Cultural Heritage, Springer. https://doi.org/10.1007/9780-387-84893-8

[7] Lin TC, Krishnaswamy G, Chi DS. (2008). Incense smoke: clinical, structural and molecular effects on airway disease, Clinical and Molecular Allergy 6: 3-11. https://doi.org/10.1186/1476-7961-6-3

[8] UNI 10829. (1999). Works of art of historical importance. Ambient condition for the conservation. Measurement and analysis, Milano: UNI Ente Nazionale Italiano di Unificazione.

[9] UNI 10969. (2002). Cultural heritage. General principles for the choice and the control of the microclimate to preserve cultural heritage in indoor environments. Milano: UNI Ente Nazionale Italiano di Unificazione; 2002.

[10] Allen R, Larson T, Sheppard L, Wallace L, Liu LJ. (2003). Use of real-time light scattering data to estimate the contribution of infiltrated and indoor-generated particles to indoor air. Environmental Science \& Technology 37(16): https://doi.org/10.1021/es021007e

[11] Weber S. (2006). Exposure of churchgoers to airborne particles. Environmental Science \& Technology 40(17): 5251-5256. https://doi.org/10.1021/es0517116

[12] Liu JL, Slaughter JC, Larson TV. (2002). Comparison of light scattering devices and impactors for particulate measurements in indoor, outdoor, and personal environments. Environmental Science \& Technology 36(13): 2977-2986. https://doi.org/10.1039/b709329m

[13] Buratti C. (2001). Analysis of the thermal stress and strain on Arrigo Fiammingo's artistic window in the cathedral of Perugia. Heat Transfer 123(6): 1173-1180. https://doi.org/10.1115/1.1404120

[14] Baer NS, Banks PN. (1985). Indoor air pollution effects on cultural and historic materials. International Journal of Museum Management and Curator Ship 4: 9-20. https://doi.org/10.1016/0260-4779(85)90049-4

[15] Brimblecombe P. (1990). The composition of museum atmospheres. Atmospheric Environment 24B (1): 1-8. https://doi.org/10.1016/0957-1272(90)90003-D

[16] Aghemo C, Dutto MG, Filippi M, Tinivella R. (1995). Analisi e valutazione delle condizioni ambientali nel museo egizio di Torino. In: Proceedings of the 50th ATI National Congress, St. Vincent 2: 907-919. https://doi.org/10.1080/0309826042000198666

[17] Pavlogeorgatos G. (2003). Environmental parameters in museum. Building and Environment 38: 1457-1462. https://doi.org/10.1016/S0360-1323(03)00113-6

[18] Camuffo D. (1991). Environment and microclimate. Science, Technology and European Cultural Heritage 3750. https://doi.org/10.1016/B978-0-7506-0237-2.500125

[19] Camuffo D. (1997). Perspectives on risks to architectural heritage. Saving Our Architectural Heritage: The Conservation of Historic Stone Structures 63-93.

[20] Cammarano S, Pellegrino A, Lo Verso VRM, Aghemo C. (2014). Assessment of daylight in rooms with different architectural features. Building Research and Information 43(2): 222-237. https://doi.org/10.1080/09613218.2014.922359

[21] Blanchette RA, Nilsson T, Daniel G, Abad A. (2000). Biological degradation of wood. Advances in Chemistry 
Series 1: 375-381. https://doi.org/10.1021/ba-19900225.ch006

[22] Singh J. (1994). Building mycology-management of decay and health in buildings. E \& FN Spon, London https://doi.org/10.1016/S0269-915X(96)80058-9

[23] Cannistraro M, Cannistraro G, Piccolo A, Restivo R. (2013). Potentials and limits of oxidative photocatalysis and possible applications in the field of cultural heritage. Advanced Materials Research 787: 111-117. https:/doi.org/10.4028/www.scientific.net/AMR.787.11 1

[24] Cannistraro M, Castelluccio ME, Germanò D. (2018). New sol-gel deposition technique in the smart-windows computation of possible applications od smart windows in buildings. Journal of Building Engineering 19: 295301. https://doi.org/10.1016/j.jobe.2018.05.0

[25] Cannistraro G, Cannistraro M, Restivo R. (2013). Messina historical buildings after the earthquake of 1908: Energy and environmental analysis through a global screening metodology. International Journal of Heat and Technology 31(2): $155-158$. https://doi.org/10.18280/ijht.310221

[26] Cannistraro M, Restivo R. (2018). monitoring of indoor microclimatic conditions od an eighteenth-century church with wireless sensors. Advances in Modelling and $\begin{array}{llll}\text { Analysis } & \mathrm{B} & 61(1): & 28-36 .\end{array}$ https://doi.org/10.18280/ama_b.610106 